\title{
TOOTH OCCLUSION PATTERN OF THE HAUSAS IN ZARIA, NIGERIA
}

\section{Ese Anibor.}

Correspondence to Dr. (Mrs.) Ese Anibor, Department of Anatomy, Faculty of Basic Medical Sciences, Delta State University, Abraka. Phone number: +2348131617679 and +2348180404966. E-mail address: eseovo2000@yahoo.com

\begin{abstract}
The study was carried out to deduce the tooth occlusion pattern among the Hausas in Zaria, Nigeria. A total of 384 subjects made up of 184 males and 200 females within the ages of 20-49 years participated in this study. Data was collected by means of questionnaire. Results revealed that mild overbite type is the commonest (male $=33.6 \%$, female $=32.6 \%$ ) which was followed by edge to edge bite (male $=13.3 \%$, female $=10.4 \%$ ). The incidence of the severe overbite was observed more in males $(3.4 \%)$ than females $(2.1 \%)$. The incidence of negative overbite was observed more in females $(2.9 \%)$ than males $(1.8 \%)$. The results showed no significant gender difference $(p \geq 0.05)$ in the tooth occlusion pattern. The tooth occlusion pattern of the Hausas in Zaria, Nigeria is such that some occlusion types are relatively more common in females than the male counterparts and vice versa. The mild overbite type of occlusion is the commonest among the Hausas in Zaria, Nigeria. The negative overbite is the least common tooth occlusion pattern among the Hausas in Zaria, Nigeria.

Key words: Nigeria; Occlusion; Pattern; Tooth; Zaria
\end{abstract}

\section{INTRODUCTION}

Dental occlusion simply refers to the contiguity between the teeth of the upper jaw (maxillary teeth) and the teeth of the lower jaw (mandibular teeth). Malocclusion means the teeth are not aligned correctly which is commonly of hereditary cause. There are distinct categories of occlusion. Eveleth's classification of tooth occlusion pattern (1972) spelt out these categories: edge to edge when the upper teeth and the lower teeth align to each other, mild overbite, when the upper teeth slightly overlap the lower teeth and severe overbite is more overlap; negative overbite is when the lower jaw overlaps the upper jaw.

Concerning tooth occlusion, the incisal thirds of mandibular incisors are covered by the vertical overlap of maxillary incisors. The amount of vertical overlap is termed overbite. An overbite which is more than three millimeters where the maxillary incisors overlap the mandibular incisors is named severe overbite. The incisors may have no vertical overlap and may present an edge to edge relationship where there is space between the incisal edges (Scheid, 2007).

Literature search reveals dearth of data on the tooth occlusion pattern of the Hausas in Zaria, Nigeria hence the need for this study. This study proffers valuable data for use in anthropology and forensic medicine. The findings from this study will also be of clinical relevance. The general objective of this study is to determine the tooth occlusion pattern of the Hausas in Zaria, Nigeria. The specific objective of this study is to identify any significant gender differences related to the tooth occlusion pattern of the Hausas in Zaria, Nigeria. This study is also concerned with producing a reliable baseline data that will be useful for further anthropometric study of the Hausas in Zaria, Nigeria.

Zaria is sited on part of the expansive, hilly to undulating Hausa lowlands of northern Nigeria which stretches almost unbroken from Sokoto in the West to the Chad basin and further on, and from south of Kaduna to the Tigueddi scarp in Republic of Niger (Thorp, 1970). 


\section{MATERIALS AND METHODS}

The study area is Zaria an urban area set in the Northern part of Nigeria. Zaria lies in the Northern part of Kaduna State. It is a historical, antique and traditional centre of the north with its administrative capital situated at Birnin Zazzau (Zaria City). It remains a politic political cynosure of the north with power bestowed solely in hands of the Emir of Zazzau (Mortimore, 1970). With the creation of the Ahmadu Bello University at Zaria in 1962, the town has become one of the rapidly growing and heavily settled metropolitan areas in north central Nigeria, flaunting accelerated mercantile and agricultural activities, metropolitanization, and population increment in the foregone three decades (Bell et al. 1999; Bell and Cheung, 2001).

This survey involved 384 subjects, the use of questionnaire, direct observation and interviews. Multistage sampling was employed, and the research subjects were aged 20 to 49 years. Both parents and grandparents of the subjects are Hausas. No history of craniofacial injury or disorder was reported by any of the subjects.

The detailed attributes of each subject suchlike age, and gender were compiled using a brief questionnaire. Tooth occlusion pattern were categorized following Eveleth's (1972) fourfold models. Subjects were classified as having any of these: edge to edge, mild overbite, severe overbite and negative overbite. Edge to edge occlusion pattern was the intimation for an

\section{RESULTS}

The incidence of mild overbite type of tooth occlusion pattern was found to be highest in both males and females, $(129,33.6 \%)$ and $(125,32.6 \%)$ followed by edge to edge, severe overbite and negative overbite with values (51, occlusion in which the incisal edges of the maxillary incisors make contact with the incisal edges of the mandibular incisors. Mild overbite is the class when the upper anterior teeth lie over the lower anterior teeth creating a vertical overlap of the anterior teeth which is 2-3 millimeters. Severe overbite is expounded when there is excess amount or percentage of vertical overlap of the lower incisors (greater than $3 \mathrm{~mm}$ or $30 \%$ percent or $1 / 3$ rd the clinical crown height of the mandibular incisors) by the upper incisors. Negative overbite is the diagnosis when the lower anterior teeth overlap the upper anterior teeth.

Ethical indorsement was obtained from the Research and Ethics Committee in the Faculty of Basic Medical Sciences of the Delta State University prior to the onset of this research. This research also had recourse to informed consent. Hence all subjects were verbally informed about the purpose of the survey and they agreed to partake. Data collection was done between the first day and the last day of the months of March and June respectively in the year 2013. Statistical analyses were accomplished using SPSS version 18. Results were set out according to gender to verify the occurrence of sexual dimorphism. The chisquare test was helpful in this regard. The tooth occlusion patterns were compared between genders. Values at $\mathrm{P}<0.05$ were regarded as been significant. 
Table 1: Tooth Occlusion Pattern of the Hausas in Zaria, Nigeria.

\begin{tabular}{|l|l|l|}
\hline \multicolumn{2}{|c|}{ GENDER } \\
\hline Tooth Occlusion Pattern & Male (\%) & Female (\%) \\
& & \\
\hline Edge to Edge & $51(13.3)$ & $40(10.4)$ \\
\hline Mild Overbite & $129(33.6)$ & $125(32.6)$ \\
\hline Severe overbite & $13(3.4)$ & $8(2.1)$ \\
\hline Negative overbite & $7(1.8)$ & $11(2.9)$ \\
\hline Total & $200(52.1)$ & $184(47.9)$ \\
\hline
\end{tabular}

\section{DISCUSSION}

The present study saw the frequency of mild overbite type as the highest (male $=33.6 \%$, female $=32.6 \%$ ) which was followed by edge to edge bite (male $=13.3 \%$, female $=10.4 \%$ ). The incidence of the severe overbite was observed more in males $(3.4 \%)$ than females (2.1\%). The incidence of negative overbite was observed more in females $(2.9 \%)$ than males $(1.8 \%)$. The results seen in the present study showed no significant gender difference $(p \geq 0.05)$. Therefore, the present study concurred with another done among the Niger Deltans in Nigeria with the frequency of mild overbite as the highest (male $=26.13 \%$, female $=25.39 \%$ ) which was followed by edge to edge type of tooth occlusion (male = $16.28 \%$, female $=18.75 \%$ ). The gender variation in the tooth occlusion pattern among the Niger Deltans was also not significant $(P>$ 0.05) (Anibor, 2016).

This study also concurred with Singh and Sengupta (2004) who did research among the Assamese Sikhs in India. They saw that the frequency of mild overbite type of tooth occlusion was found to be the highest (male = $44.90 \%$, female $=54.00 \%$ ) which was closely followed by edge to edge bite (male $=36.73 \%$, female $32.0 \%$ ). They noted bisexual variation with no significant differences $(0.80>\mathrm{P}>$ 0.70) among the Indians.

The present study seems not to agree with that done by Singh and Sengupta (2004). They observed incidence of negative overbite to be more in males $(16.33 \%)$ than females $(10.00 \%)$. The severe overbite type was rare among them.

The present study did not concur with another done by Anibor et al., in 2014. They observed that females have a higher percentage frequency of the mild overbite occlusion pattern followed by the edge to edge bite. They also noted that the females have equal percentage distribution of severe overbite and negative overbite. Their study revealed that males have highest percentage of the edge to edge bite followed by the mild overbite, negative overbite and severe overbite (Anibor et al., 2014).

The different studies reviewed above depicted differences in the tooth occlusion pattern considered. There may be reasons for this such as ethnicity, nationality, race, methodology and age.

In conclusion, the tooth occlusion pattern of the Hausas in Zaria, Nigeria has been studied. Some occlusion patterns have been shown to be relatively more common in females than the male counterparts and vice versa. The mild overbite type of occlusion was the commonest among the Hausas in Zaria, Nigeria. The negative overbite is the least common tooth occlusion pattern among the Hausas in Zaria, Nigeria. 


\section{REFERENCES}

1. Angle EH. 1899. Classification of malocclusion. Dental Cosmos. 41: 248-264.

2. Anibor E. 2016. The Tooth Occlusion Pattern among the Niger Deltans in Nigeria. Nigerian Biomedical Science Journal, 12 (2): 10-12.

3. Anibor E, Edjomariegwe O, Ajayi A. 2014. Genetic and morphological traits among the Binis. International Journal of Current Research, 6 (11): 10222-10227.

4. Bell DVJ. 2001. Sustainable urban communities in Canada: From Rio to Johannesburg. York Centre for Applied Sustainability York University. Prepared under contract for Stratos as background documentation for the report of the Government of Canada to the World Summit.

5. Bell DVJ, Tilman A, Cheung A. 1999. Advancing sustainability in the great lakes basin, York Centre for Applied Sustainability York University. Prepared for Environment Canada.

6. Eveleth PB. 1972. An anthropometric study of North Eastern Brazilians. American Journal of Physical Anthropology, 37: 223.

7. Mortimore MJ. 1970. Zaria and its Region, Occasional paper No. 4 Department of Geography, A.B.U. Zaria, published for the 14th Annual conference of Nigerian Geographical Association, Zaria. Pp 15.

8. Schied RC. 2007. Woelfe's Dental Anatomy: its relevance to dentistry. 7th ed. Williams and Wilkins, Baltimore. P. 54-58.

9. Singh J, Sengupta S. 2004. Some Morpho-genetic and Behavioural Traits among the Assamese Sikhs. Anthropologist, 6 (4): 253-255.

10. Thorp MP. 1970. Landforms cited in Zaria and its region, Mortimore M.J. (ed.) Occasional paper No. 4 Department of Geography, A.B.U., Zaria. 13-18 